\title{
CORRESPONDENCE
}

We welcome letters to the Editor concerning articles which have recently been published. Such letters will be subject to the usual stages of selection and editing; where appropriate the authors of the original article will be offered the opportunity to reply.

Letters should normally be under 500 words in length, doublespaced throughout, signed by all authors and fully referenced. The edited version will be returned for approval before publication.

\section{PARTICLES IN LOOSE HIPS}

Sir,

In their paper in your May 1992 issue on 'Size of metallic and polyethylene debris particles in failed cemented total hip replacements' (1992:74-B:380-4) Lee and his colleagues have contributed important data on particulate debris dimensions in the tissues surrounding failed cemented hip components, but their paper leaves some key methodological questions unanswered. Particle isolation and characterisation are highly sensitive processes and their report warrants critical review.

First, accurate measurement by light microscopy and image analysis can be difficult in the absence of size standards, which were not reported to be used by the authors. Secondly, they do not detail their criteria for light-microscopic identification of polyethylene debris, which were analysed only by image analysis of paraffin sections. This method is inherently restricted to relatively large particles and may give the false impression that smaller, more biologically reactive particles do not exist. Admittedly, the collection and identification of submicron polymeric particulates are technically challenging, but preliminary reports on the use of Oil Red $\mathrm{O}$ to stain intracellular polyethylene debris have suggested that this material is abundant in periprosthetic tissues and is found in significantly more cells than contain polarisable material (Campbell et al 1992a: Schmalzreid et al 1992). Transmission electron microscopy also supports the presence of multiple, submicron particulates of polyethylene within periprosthetic macrophages from these cases (Schmalzreid, Jasty and Harris 1992). We have shown, using photon correlation spectroscopy, that submicron particulates with an average size of $300 \mathrm{~nm}$ could comprise as much as $1 \%$ of the mass weight of periprosthetic tissues (Kossovsky et al 1992) and that these particulates are found in amounts much greater than could be detected by routine histological examination (Campbell et al 1992b). In these studies, submicron particulates were successfully collected only when digestants were centrifuged with accelerations of the order of $60000 \mathrm{~g}$ for 90 minutes which are significantly higher and of longer duration than the approximately $10000 \mathrm{~g}$ for 15 minutes used by Lee et al.

Transmission electron microscopy is effective in visualising intracellular particles but is limited by inadequate sampling and the fact that larger particles do not survive the sectioning process and often damage adjacent tissues that may contain smaller particulates. Automated characterisation of isolated particulates by photon spectroscopic or electrical impedance

(C) 1993 British Editorial Society of Bone and Joint Surgery $0301-620 X / 93 / 1502 \$ 2.00$

J Bone Joint Surg [ Br] 1993; 75-B:161-5. techniques is the preferred method for small particle analysis because a much greater volume of particulates may be measured rapidly and a more comprehensive size distribution may be obtained.

Lee et al are to be commended for their work but their data, and their conclusions from it, must be examined in view of the limitations of their techniques. In particular, by not applying the tissue digestion method or transmission electronmicroscopic techniques to polyethylene particulates, the authors may be overlooking the significance of this material in the aseptic loosening process.

P. CAMPBELL. BSC

N. KOSSOVSK Y, MD

T. P. SCHMALZRIED. MD

Implant Retrieval Laboratory

Joint Replacement Institute

Los Angeles

California, USA.

Campbell P, Chun G, Kossovsky N, Amstutz HC. Histological analysis of tissues suggests that 'metallosis' may really be 'plasticosis'. Trans Orthop Res Soc. Washington DC, 1992a.

Campbell P, Gelman A, Kossovsky N, Amstutz HC. Submicrometre particulates in human periprosthetic tissues. In: Sudarshan TS, ed. Surface modification technologies $V$. The Institute of Metals, $1992 \mathrm{~b}$.

Kossovsky N, Liao K, Gelman A, Campbell P, et al. Photon correlation spectroscopy analysis of the submicrometre particulate fraction in human synovial tissues recovered at arthroplasty or revision. Amer Soc for Testing Materials Special Technical Publication 1144 Philadelphia, 1992

Lee J-M, Salvati EA, Betts F, DiCarlo EF, Doty SB, Bullough PG. Size of metallic and polyethylene debris particles in failed cemented total hip replacements. J Bone Joint Surg [ Br] 1992; 74-B:380-4.

Schmalzried TP, Jasty M, Harris WH. Periprosthetic bone loss in total hip arthroplasty: the role of polyethylene wear debris and the concept of the effective joint space. J Bone Joint Surg [Am] 1992; in press.

Schmalzried TP, Jasty M, Rosenberg A, Harris WH. Histologic identification of polyethylene wear debris using Oil Red O stain. $J$ Appl Biomat 1992; in press.

Reply from some of the authors:

Sir.

Dr Campbell and her colleagues have perhaps read our paper with somewhat more imagination than it was written. We aimed to determine any relationship between particle size, both metal and polyethylene, in failed prostheses manufactured of different metals.

We agree that particle isolation and measurement are both highly sensitive to the methods used. This is borne out by the very large discrepancy in mean and (particularly) standard deviation of metal particle size yielded by our two methods. Our report gave a number of limitations of each method, including problems with detecting very small particles. In view of these difficulties, we based our conclusions largely on the fact that little difference in particle size was seen among the different alloys for either method.

There are a number of problems relating both to the isolation methods that we used and those suggested by Dr Campbell and her colleagues. Very small metal particles, particularly of cobalt alloy, may dissolve to a considerable extent in aqueous media, as may be verified by measuring metal 
concentrations in the liquid. We therefore used an organic base in non-polar organic liquid which, unfortunately, is a solvent for polyethylene, so that we were unable to detect polyethylene particles by this method. Problems of aggregation and colloidal suspension of very small particles, which may be quite severe in aqueous media, were considerably less, however, due both to the lower density $(0.85 \mathrm{~g} / \mathrm{ml})$ and non-polar nature of the solvent, permitting us to use a less rigorous centrifugation.

The criteria that we have used for identifying polyethylene debris for over 20 years, are morphological, and depend on the use of polarised light with strain-free lenses. Striking quantities of polyethylene can be seen in many cases of implant failure including fine intracellular fragments. We remain unconvinced of the usefulness of Oil Red $\mathrm{O}$ stain in demonstrating particles of polyethylene. We have seen one recently published polarised photomicrograph using Oil Red O stain (Peters et al 1992) that shows polyethylene. The staining results, however, are such that it would still seem impossible to resolve the particles with any degree of precision at the light-microscopic level, and quantification would therefore not be possible.

An electron micrograph was included in our paper to show that very small metal particles are indeed found intracellularly, and we too have seen submicroscopic particles of polyethylene, but our conclusions were based principally on the metal data, and the fact that no significant difference in particle size was seen among the three different alloys.

We did not overlook the significance of polyethylene debris : it is specifically mentioned in our concluding paragraph. In a recent paper (Betts et al 1992), we showed that cemented cobalt-alloy prostheses could become loose with the presence of extremely small amounts of metal debris and suggest that polymeric debris, at least in these cases, may be the principal cause of aseptic loosening.

The results reported by Dr Campbell and her colleagues by using Oil Red O stain and photon-correlation spectroscopy are interesting. As these methods become used by other investigators and their reproducibility as well as their limitations more thoroughly explored, it is possible that they may yet become "preferred methods".

F. BETTS, PhD

P. G. BULLOUGH, MB ChB

E. F. DiCARLO, MD

Hospital for Special Surgery

535 East 70th Street

New York, USA.

Betts F, Wright T, Salvati E, Boskey A, Bansal M. Cobalt alloy metal debris in periarticular tissues from total hip revision arthroplasties. Clin Orthop 1992; 276:75-82.

Peters PC Jr, Engh GA, Dwyer KA, Vinh TN. Osteolysis after total knee arthroplasty without cement. J Bone Joint Surg [Am] 1992; 74A : $864-76$

\section{HIP SOCKET IMPINGEMENT}

Sir.

May I comment on the article in your May 1992 issue by Mr D. $\mathrm{W}$. Murray on 'Impingement and loosening of the long posterior wall acetabular implant' (1992:74-B:377-9)?

Charnley introduced the long posterior wall (LPW) socket for two reasons: first, to be able to maintain the neutral orientation of the socket while achieving the benefit of acetabular anteversion, and secondly, to reassure those surgeons who believed that the small head was more likely to dislocate after operation. Charnley was concerned that it would not be possible to convey to others the strictly defined degree of anteversion of the socket needed at surgery. This concern seems to have been justified - Mr Murray's statement ". . . $6^{\circ}$ of socket anteversion.... and the femoral component in the standard position with some anteversion..." clearly illustrates this point. It would be difficult to reproduce this accurately, but the neutral position leaves no doubt.

The appearance of the socket in Figure 1 of Mr Murray's article is unusual if the cause was the impingement of the neck of the stem on the socket rim. True impingement leads to a smooth flattening of the margin of the socket bore. The roughness seen in Figure 1 is more in keeping with recurrent posterolateral subluxation/dislocation in which the roughened head of the femoral component and particles of the acrylic cement are dragged to and fro across the socket rim. The erosion associated with prosthetic penetration is again different; the circular appearance changes into an ellipse.

It may not be possible to prove that the LPW socket has reduced the already low incidence of postoperative dislocation. Our results from the Hip Centre show a revision rate for recurrent dislocation of $0.11 \%$ (Fraser and Wroblewski 1981 ).

The LPW socket has a flange for improving cement injection. The introduction of the flanged socket has increased the survivorship from $90 \%$ at 15 to 25 years to $97 \%$ at 10 to 17 years (Wroblewski and Siney 1991).

\section{B. M. WROBLEWSKI, FRCS}

Centre for Hip Surgery

Wrightington Hospital for Joint Disease

Appley Bridge

Wigan, UK

Fraser GA, Wroblewski BM. Revision of the Charnley low-friction arthroplasty for recurrent or irreducible dislocation. J Bone Joint Surg $[\mathrm{Br}] 1981 ; 63-\mathrm{B}: 552-5$

Murray DW. Impingement and loosening of the long posterior wall acetabular implant. J Bone Joint Surg [Br] 1992; 74-B:377-9.

Wroblewski BM, Siney P. Charnley low-friction arthroplasty: a study of results in young patients. J Bone Joint Surg 1991; 73-B :Supp I; 71

\section{Reply from the author:}

Sir,

Thank you for the opportunity to reply to Professor Wroblewski's letter.

If erosion of the margin of a socket is caused by recurrent subluxation/dislocation then I would expect the inside of the socket to merge smoothly into the eroded margin. If caused by impingement then I would expect a sharp transition between the inside of the socket and the eroded margin, possibly with a build-up of polyethylene on the inside of the socket where this meets the eroded margin. My Figure 1 demonstrates this latter appearance and $I$ believe therefore that in this case the erosion was caused by impingement. There is no doubt that impingement on the LPW does occur (Charnley 1979). The torques generated by impingement will cause shear stresses at the cement-bone interface, which in turn will encourage loosening. It is therefore essential that these impingement torques be minimised. LPW sockets induce much larger torques than standard sockets, and are therefore theoretically more likely to loosen.

In my paper I intentionally avoided discussing the actual socket anteversion; instead I discussed the relative anteversion of LPW and standard sockets. The question of actual orientation has now been raised. The normal acetabulum is anteverted. To reproduce this an acetabular socket either has to be anteverted or has to be asymmetrical like a LPW socket. An anteverted socket will have optimal and equal bone cover both anteriorly and posteriorly, whereas a socket in neutral will either be uncovered anteriorly or there will be exposed bone posteriorly. Using a jig it is not difficult to antevert a socket by the required amount, which although controversial is about $20^{\circ}$ (Harris 1980). The orientation can be checked as the margin of the 